\title{
Evaluation of resilient modulus and unconfined compressive strength of subgrade
}

\author{
Dian Hastari Agustina ${ }^{1, *}$, Adnan Zainorabidin ${ }^{1}$ \\ ${ }^{1}$ Faculty of Civil and Environmental Engineering, University Tun Hussein Onn Malaysia, 86400, Batu Pahat, Johor, Malaysia
}

\begin{abstract}
Subgrade soil is the important material as the foundation for supporting the pavement layers and the repeated load of vehicle traffic. To characterize the stiffness and strength behavior of subgrade due to traffic loading in structural pavement design can be determined by resilient modulus and unconfined compressive strength test. In this study, laboratory test of resilient modulus and unconfined compressive strength used to investigate (1) the effect of moisture content of the changes of stiffness and strength characteristics, (2) the correlation between the resilient modulus and elasticity modulus. The soil sample prepared at five type of compacted soils, at the dry side (OMC-20\%OMC and OMC-10\%OMC), OMC and at the wet side $(\mathrm{OMC}+10 \% \mathrm{OMC}$ and $\mathrm{OMC}+20 \% \mathrm{OMC})$. The result shows the moisture content has a significant effect on cohesive soil, the resilient modulus, modulus elasticity and stress value increase with the increase of moisture content until reaching the optimum moisture content (OMC) and then decrease with the increase of moisture content on the wet side of OMC point. By comparing both resilient modulus and unconfined compressive strength result from ANOVA statistics analysis can be concluded that there is no difference in stiffness between resilient modulus and modulus elasticity methods.
\end{abstract}

\section{Introduction}

Resilient modulus $\left(\mathrm{M}_{\mathrm{R}}\right)$ is a measure of subgrade material stiffness while the modulus of elasticity (E) is a parameter that used to measure material or the resistance of material to elastic deformation when load is applied. Resilient modulus $\left(\mathrm{M}_{\mathrm{R}}\right)$ is stress divided by strain for rapidly applied loads and modulus of elasticity is stress divided by strain for a slowly applied load. Resilient modulus $\left(\mathrm{M}_{\mathrm{R}}\right)$ requires input for determining the stress, strains deflection in pavement design. Modulus of elasticity can be deformed for any solid material and representation of the stress strain ratio. The ability of materials to return to its original shape after release the stress applied is called stiffness. Stiffness is also the degree to which an object resists its deformation in applied load.

Soil is a material that influences by moisture content, soil texture, density, and strength. The performance of the pavement is influenced by the characteristics of the soil subgrade [1]. Subgrade may consist of natural soil, either cut or fill which supports the pavement systems [2]. Subgrade is close to the soil surface, the conditions will always be effected by changes in climate [3]. It causes water levels fluctuate so that will effect to the soil strength and stiffness especially on clay soil. Subgrade can significantly affected by variation of moisture content. In a few decades, some researchers have studied the influence of moisture content on resilient modulus of subgrade soils $[4,5,6,7]$. The moisture content of subgrade soils is one of the most important variable to

\footnotetext{
* Corresponding author: dian rajendra@yahoo.com
}

predict the resilient modulus $\left(\mathrm{M}_{\mathrm{R}}\right)$ value $[8,9]$. The resilient modulus increases due to increasing moisture content until it reaches the optimum moisture content, and the increase of water content next will cause a decrease on the resilient modulus $[3,4,9]$.

The objective of this research is to show the effect of moisture content of subgrade and the correlation between the resilient modulus value and elasticity modulus from the unconfined compressive strength test. Several researchers have also been done regarding the relationship between resilient modulus $\left(\mathrm{M}_{\mathrm{R}}\right)$ and unconfined compressive strength (UCS), either to estimate the resilient modulus $\left(\mathrm{M}_{\mathrm{R}}\right)$ value based on the UCS test or to see the interaction between resilient modulus and unconfined compressive strength value [1013].

The resilient modulus is a stress-strain relationship and can be defined as the ratio of axial deviator stress to recoverable axial strain. The resilient modulus $\left(\mathrm{M}_{\mathrm{R}}\right)$ was calculated from the load and deformation using the following equation:

$$
\mathrm{M}_{\mathrm{R}}=\sigma_{\mathrm{d}} / \varepsilon_{\mathrm{r}}
$$

Where

$\mathrm{M}_{\mathrm{R}}$ is resilient modulus

$\sigma_{\mathrm{d}}$ is axial deviator stress

$\varepsilon_{\mathrm{r}}$ is recoverable (resilient) strain. 
Fig. 1 shows the illustration of behavior of permanent strain resilient modulus under repeated load [13].

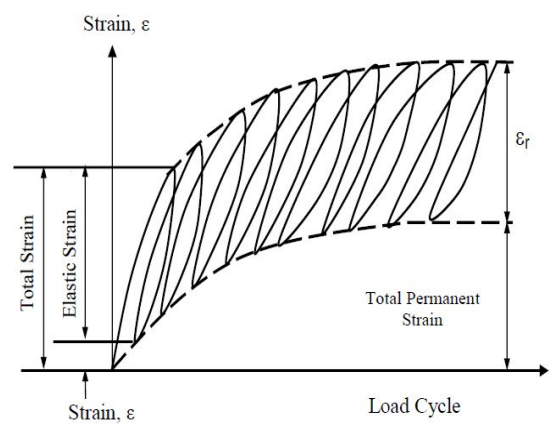

(a)

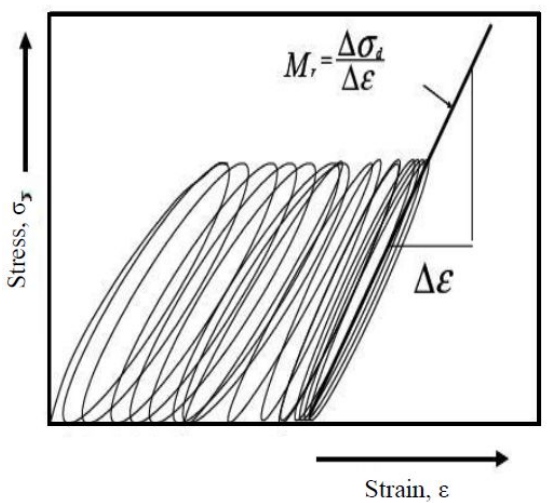

(b)

Fig. 1. (a) Behavior of specimen under repeated load and (b) Resilient modulus

Modulus of elasticity (E) of a material can be defined as the ratio between stress $(\Delta \sigma)$ and strain $(\Delta \varepsilon)$ that occur to the soil due to loading, or can be formulated as below.

$$
\mathrm{E}=\Delta \sigma / \Delta \varepsilon
$$

Where

$\mathrm{E}$ is modulus elasticity

$\Delta \sigma$ is stress

$\Delta \varepsilon$ is strain

Each type of soil has a different modulus of elasticity, its depending on the type of soil, besides external factors such as compaction and moisture content also affects the value of the modulus of soil elasticity.

\section{Materials and methods}

\subsection{Materials}

The soil subgrade sample taken from the Research Centre of Soft Soils Universiti Tun Hussein Onn Malaysia (RECESS, UTHM) at a depth of 2 meters.

The physical properties were determined using atterberg limits, specific gravity, sieve analysis, standard proctor test. The standard proctor compaction test is used to determine the maximum dry density (MDD) and optimum moisture content (OMC) based on guidelines of BS (1993) part 4. Table 1, shows the summary of the soil properties data of the clay soil.

Table 1. Data properties of clay soil [14]

\begin{tabular}{l|l}
\hline Soil Properties & Value \\
\hline Natural moisture content (\%) & 92.88 \\
\hline Atterberg limit : & \\
Liquid limit (\%) & 55.54 \\
Plastic limit (\%) & 24.58 \\
Plasticity index (\%) & 30.96 \\
\hline Specific gravity & 2.61 \\
\hline Particles: & \\
Gravel fraction, percent retained above & 0 \\
sieve 4,75 mm (\%) & \\
Coarse fraction, percent retained above & 5.87 \\
sieve 0.075 mm (\%) & 94.13 \\
Fine fraction, percent passing sieve & $\mathrm{CH} / \mathrm{A}-7-6$ \\
\hline USCS / AASHTO Classification & $28 \%$ \\
\hline Optimum Moisture Content (OMC) (\%) & 1.84 \\
\hline Maximum Dry Density (MDD) gr/cm ${ }^{3}$ & \\
\hline
\end{tabular}

The compaction curve shows that the dry density increase as the increase of moisture content after it achieved the optimum moisture content, the dry density will decrease as the increase of the moisture content increase. Maximum dry density (MDD) obtained at 1.84 $\mathrm{g} / \mathrm{cm} 3$ and optimum moisture content (OMC) at $28 \%$.

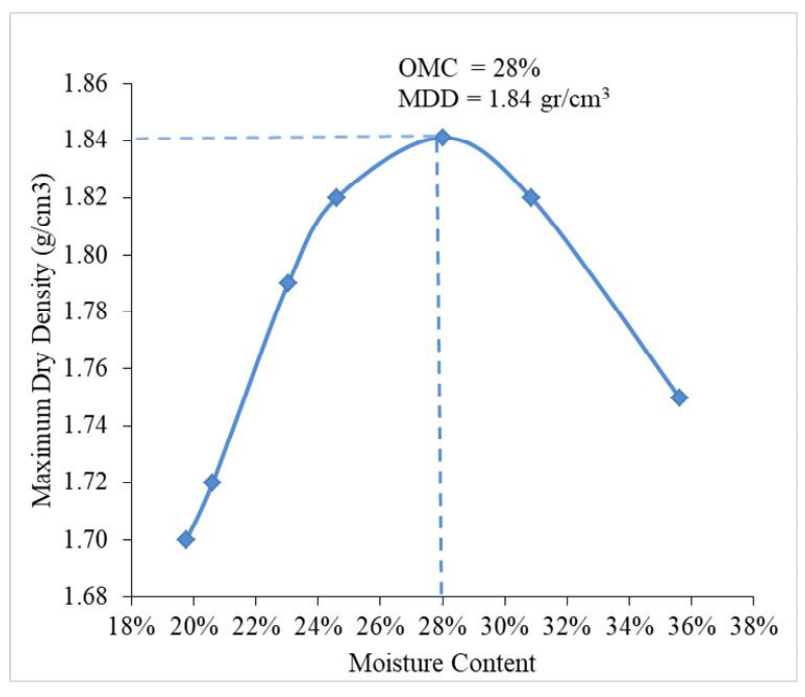

Fig. 2. Compaction curve for clay soil

\subsection{Methods}

The resilient modulus test was done on fine materials as per the standard of AASHTO T.307, the soil samples tested using the machine Load Trac II (Geocomp). According to the standard, the soil sample was classified as type II (fine grained). The soil samples dimension for tested of $50 \mathrm{~mm}$ diameter and height of $100 \mathrm{~mm}$. 


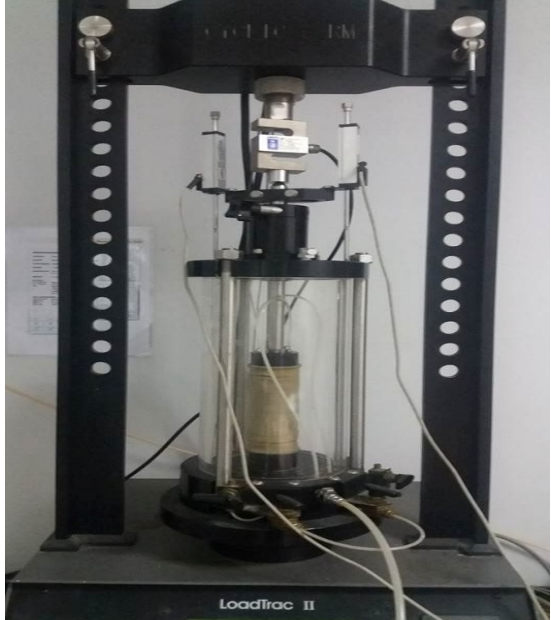

Fig. 3. GEOCOMP fully automated resilient modulus machine

The resilient modulus test is conducted in 15 sequences that consist of two phases. The first phase, the test began with a conditioning phase (sequence 0 ) which consists of applying 500-1000 repetitions of the load and further followed by the second phase (sequence 1 until 15), which the specimen is submitted to cycle loading that consists of applying 100 repetitions of load. The cyclic axial stress using a haversine-shape that consists of a 0.1 second load pulse, then followed by a 0.9 second rest period. Table 2 shows the testing sequence that applied.

Table 2. Testing sequence for subgrade soil (Type II) [15]

\begin{tabular}{|c|c|c|c|}
\hline \multirow[t]{2}{*}{$\begin{array}{c}\text { Sequence } \\
\text { No. }\end{array}$} & $\begin{array}{c}\text { Confining } \\
\text { Pressure } \\
\left(\sigma_{3}\right)\end{array}$ & $\begin{array}{c}\text { Deviator } \\
\text { Stress } \\
\left(\sigma_{\mathrm{d}}\right)\end{array}$ & \multirow[t]{2}{*}{$\begin{array}{l}\text { Load } \\
\text { repetition }\end{array}$} \\
\hline & $\mathrm{kPa}$ & $\mathrm{kPa}$ & \\
\hline Cond & 41.4 & 27.6 & $500-1000$ \\
\hline 1 & & 13.8 & 100 \\
\hline 2 & & 27.6 & 100 \\
\hline 3 & 41.4 & 41.4 & 100 \\
\hline 4 & & 55.2 & 100 \\
\hline 5 & & 68.9 & 100 \\
\hline 6 & & 13.8 & 100 \\
\hline 7 & & 27.6 & 100 \\
\hline 8 & 27.6 & 41.4 & 100 \\
\hline 9 & & 55.2 & 100 \\
\hline 10 & & 68.9 & 100 \\
\hline 11 & & 13.8 & 100 \\
\hline 12 & & 27.6 & 100 \\
\hline 13 & 13.8 & 41.4 & 100 \\
\hline 14 & & 55.2 & 100 \\
\hline 15 & & 68.9 & 100 \\
\hline
\end{tabular}

The unconfined compression strength test is used to measure the shearing resistance of cohesive soils which may be undisturbed or remolded specimens. An axial load is applied using either strain-control or stresscontrol condition. The unconfined compressive strength is defined as the maximum unit stress obtained within the first $20 \%$ strain. The UCS test performed on a cylindrical sample having a ratio of height to diameter is $2: 1$, this research used a soil sample dimension with a diameter of $38 \mathrm{~mm}$ and a height of $76 \mathrm{~mm}$.

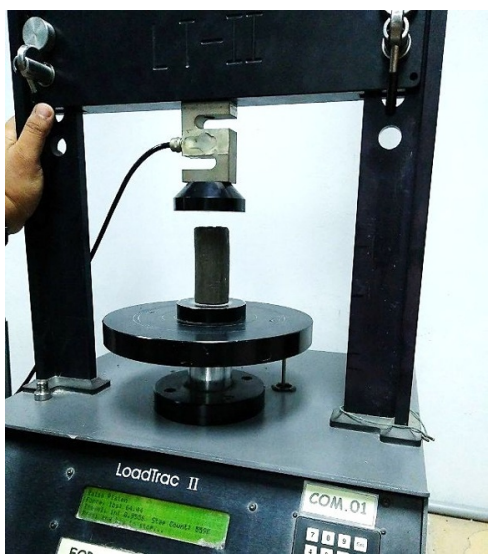

Fig.4. The unconfined compressive strength test machine

\section{Result and discussions}

\subsection{Resilient modulus and unconfined compressive strength test result}

Each sample has been compacted at five different moisture contents for resilient modulus $\left(\mathrm{M}_{\mathrm{R}}\right)$ test and unconfined compressive strength (UCS) test.

Table 3. Moisture content for soil testing

\begin{tabular}{l|c|c|c}
\hline $\begin{array}{c}\text { Moisture } \\
\text { Condition }\end{array}$ & $\begin{array}{c}\text { Target } \\
\text { moisture } \\
\text { content } \\
(\%)\end{array}$ & $\begin{array}{c}\text { Moisture } \\
\text { content of } \\
\text { MR test } \\
(\%)\end{array}$ & $\begin{array}{c}\text { Moisture } \\
\text { content of } \\
\text { UCS test } \\
(\%)\end{array}$ \\
\hline OMC-20\%*(OMC) & 22.4 & 21.87 & 20.90 \\
OMC-10\%*(OMC) & 25.2 & 24.65 & 25.08 \\
OMC & 28 & 27.85 & 27.87 \\
OMC+10\%*(OMC) & 30.8 & 30.23 & 30.54 \\
OMC+20\%*(OMC) & 33.6 & 33.34 & 33.55 \\
\hline
\end{tabular}

Table 4, shows the result of resilient modulus for 15 sequences from five various of moisture content. The result of resilient modulus at optimum moisture content (OMC) have higher values than other moisture content at dry side and wet side of OMC.

Table 5, shows the mean of resilient modulus and UCS test results for each moisture content. Fig. 5 and 6 , shows the trend of the curve of $M_{R}$ versus qu and $M_{R}$ versus elasticity modulus has a similar curve as OMCMDD curve. It can be explained that when the soil sample is not at the OMC point (at the dry side and wet side), the dry density of soil is lower than maximum dry density condition. It causes the resilient modulus also have the lower value than at the OMC point. The addition of more water to soil can produce its saturation and it's very difficult to compact, also if compacted soil at low moisture content. 
Table 4. Resilient modulus at various of moisture content

\begin{tabular}{|c|c|c|c|c|c|c|c|}
\hline \multicolumn{3}{|c|}{ Stress } & \multicolumn{5}{|c|}{ Resilient modulus (Mpa) } \\
\hline$\sigma_{3}(\mathrm{kPa})$ & $\sigma_{\mathrm{d}}(\mathrm{kPa})$ & $\theta(\mathrm{kPa})$ & $\begin{array}{c}\text { OMC - } \\
20 \% \text { OMC }\end{array}$ & $\begin{array}{c}\text { OMC - } \\
10 \% \mathrm{OMC}\end{array}$ & OMC & $\begin{array}{c}\mathrm{OMC}+ \\
10 \% \mathrm{OMC}\end{array}$ & $\begin{array}{c}\text { OMC + } \\
20 \% \mathrm{OMC}\end{array}$ \\
\hline 41.40 & 13.80 & 138.00 & 192.25 & 225.67 & 245.51 & 263.73 & 182.53 \\
\hline 41.40 & 27.60 & 151.80 & 175.44 & 218.21 & 279.33 & 244.13 & 168.01 \\
\hline 41.40 & 41.40 & 165.60 & 163.56 & 207.28 & 261.39 & 213.67 & 161.07 \\
\hline 41.40 & 55.20 & 179.40 & 158.50 & 195.07 & 246.35 & 200.60 & 139.04 \\
\hline 41.40 & 68.90 & 193.10 & 143.80 & 181.13 & 251.37 & 205.97 & 122.45 \\
\hline 27.60 & 13.80 & 96.60 & 137.15 & 195.95 & 231.81 & 195.00 & 151.14 \\
\hline 27.60 & 27.60 & 110.40 & 133.90 & 202.50 & 229.81 & 167.00 & 141.26 \\
\hline 27.60 & 41.40 & 124.20 & 126.08 & 182.15 & 214.44 & 167.00 & 130.56 \\
\hline 27.60 & 55.20 & 138.00 & 126.00 & 156.90 & 239.66 & 156.00 & 131.66 \\
\hline 27.60 & 68.90 & 151.70 & 122.29 & 151.89 & 232.98 & 139.00 & 120.35 \\
\hline 13.40 & 13.80 & 54.00 & 129.46 & 170.70 & 239.27 & 143.11 & 147.89 \\
\hline 13.40 & 27.60 & 67.80 & 131.78 & 167.76 & 212.25 & 124.91 & 145.56 \\
\hline 13.40 & 41.40 & 81.60 & 129.35 & 156.77 & 209.00 & 130.92 & 145.36 \\
\hline 13.40 & 55.20 & 95.40 & 127.50 & 143.98 & 212.19 & 128.99 & 126.10 \\
\hline 13.40 & 68.90 & 109.10 & 120.53 & 129.58 & 210.56 & 127.78 & 124.38 \\
\hline
\end{tabular}

Table 5. Mean of $M_{R}$ versus UCS test result

\begin{tabular}{l|c|c|c|c|c}
\hline & $\begin{array}{c}\text { OMC- } \\
20 \% \text { OMC }\end{array}$ & $\begin{array}{c}\text { OMC- } \\
10 \% \text { OMC }\end{array}$ & OMC & $\begin{array}{c}\text { OMC+ } \\
10 \% \text { OMC }\end{array}$ & $\begin{array}{c}\text { OMC+ } \\
20 \% \text { OMC }\end{array}$ \\
\hline Mean $\mathrm{M}_{\mathrm{R}}(\mathrm{MPa})$ & 141.17 & 153.76 & 234.39 & 173.85 & 142.49 \\
Stress $(\mathrm{kPa})$ & 189.68 & 249.74 & 253.53 & 220.97 & 183.34 \\
$\mathrm{E}(\mathrm{kPa})$ & 143 & 183 & 236 & 179 & 145 \\
\hline
\end{tabular}

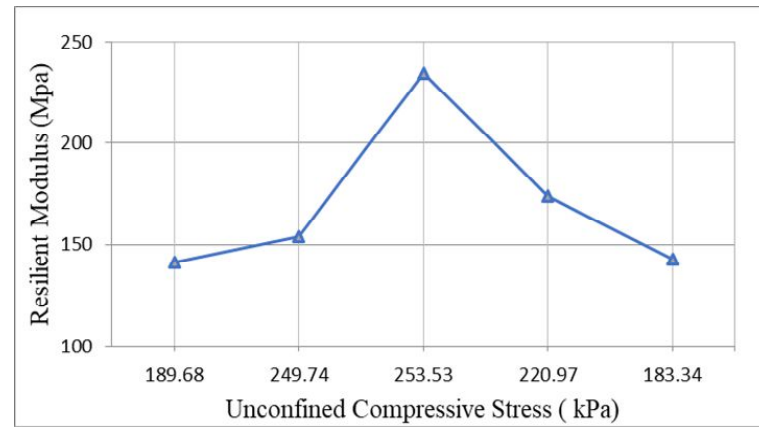

Fig. 5. $M_{R}$ versus $q_{u}$ at various moisture content

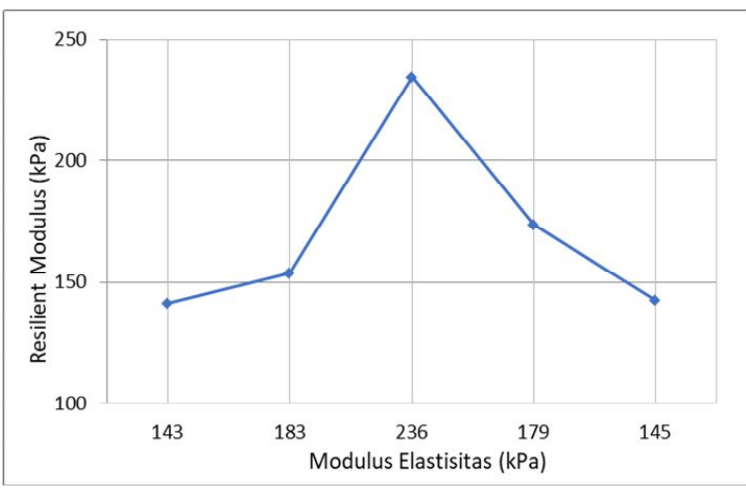

Fig. 6. $M_{R}$ versus $E$ at various moisture content

From the $M_{R}$ and $E$ curve of five different moisture content shows that the maximum stress reached at the optimum moisture content (OMC), the same as the curve of $\mathrm{M}_{\mathrm{R}}$ and $\mathrm{q}_{\mathrm{u}}$ this is because at OMC condition, maximum dry density is at the highest point.
Table 6. The percentage changes of value $M_{R}$, $q_{u}$ and $E$

\begin{tabular}{c|c|c|c|c|c}
\hline $\mathbf{M}_{\mathbf{R}}$ & $\Delta \mathbf{M}_{\mathbf{R}}$ & $\mathbf{E}$ & $\Delta \mathbf{E}$ & $\mathbf{q}_{\mathbf{u}}$ & $\Delta \mathbf{q}_{\mathbf{u}}$ \\
\hline 141.17 & $39.77 \%$ & 143 & $39.41 \%$ & 189.68 & $25.19 \%$ \\
\hline 179.04 & $23.61 \%$ & 183 & $22.46 \%$ & 249.74 & $1.49 \%$ \\
\hline 234.39 & $0.00 \%$ & 236 & $0.00 \%$ & 253.53 & $0.00 \%$ \\
\hline 173.85 & $25.83 \%$ & 179 & $24.15 \%$ & 220.97 & $14.74 \%$ \\
\hline 142.49 & $39.21 \%$ & 145 & $38.56 \%$ & 183.34 & $27.68 \%$ \\
\hline
\end{tabular}

Table 6, shows the percentages of changes of resilient modulus $\left(\mathrm{M}_{\mathrm{R}}\right)$ and modulus elasticity (E) from the dry side to $\mathrm{OMC}$ and wet side to $\mathrm{OMC}$ have a value that almost close to the same, but different with the stress $\left(\mathrm{q}_{\mathrm{u}}\right)$ result. It is because the resilient modulus and modulus elasticity is the same parameter to measure the stiffness parameter, although it has the differences of procedure of testing whereas stress $\left(\mathrm{q}_{\mathrm{u}}\right)$ is strength parameter.

\section{3. $M_{R}$ and $E$ correlation}

Statical analysis is used to compare groups means. ANOVA (analysis of variance) was used in this research where the effect of moisture content was used as the basis for analysis the resilient modulus $\left(M_{R}\right)$ and modulus elasticity (E) values. The effect is considered statically significant for p-value of less than 0.05 and insignificant for $p$-value greater than 0.05 . This value means significant level provides $95 \%$ confidence result and only $5 \%$ probability of committing.

Table 7. Anova

\begin{tabular}{|l|c|c|c|c|c|c|}
\hline Source of Variation & SS & $d f$ & MS & $F$ & P-value & F crit \\
\hline Between Groups & 4463.206 & 1 & 4463.206 & 3.580587 & 0.095097 & 5.317655 \\
\hline Within Groups & 9972.009 & 8 & 1246.501 & & & \\
\hline & & & & & & \\
\hline Total & 14435.21 & 9 & & & & \\
\hline
\end{tabular}

The ANOVA table above shows the value of $\mathrm{p}$ value is greater than 0.05 (alpha), then the decision to accept $\mathrm{H} 0$ means there is no difference in the average of each group. Besides, it can be seen by comparing the value of $F$ (3.5805) with $F$ crit (5.3176). It can be seen that $F$ is smaller than $\mathrm{F}$ crit, then the same decision is received H0. So it can be concluded that there is no difference in stiffness between resilient modulus and modulus elasticity methods.

\section{Conclusion}

The value of resilient modulus, modulus elasticity and also the stress, increased with an increasing of moisture content until it reaches the optimum moisture content, the increase of water content next will cause a decrease on resilient modulus, modulus elasticity and stress. Moisture content has a significant effect on cohesive soil type on the dry-wet conditions, this causes the decrease of resilient modulus, modulus elasticity and stress. Resilient modulus of subgrade is one of the key material properties that is required for pavement design and analysis. Cyclic repeated load that is used on the resilient 
modulus test is used to simulate the traffic load condition. Modulus elasticity from UCS test also can used as to evaluate the stiffness of subgrade. The resilient modulus of subgrade is not strength but stiffness where a subgrade can support a high amount of load applied with very slight deformation.

\section{References}

1. E.J. Yoder, M.W. Witczak, Principles of Pavement Design, J Wiley and Sons Inc, second edition (1975)

2. M.P. O'Reilly, S.F. Brown, Cyclic loading of Soils : From Theory to Design, Blackie and Sons, Ltd. London (1991)

3. G. Baladi, T. Dawson, C. Sessions, Pavement Subgrade MR Design Values for Michigan's Seasonal Changes, Report No. RC-1531, Tech. Report, Michigan Department of Transportation (2009)

4. B.T. Nguyen, A. Mohajerani, J. Aust. Geomech. Society 49 (2) 73-84 (2014)

5. R. Ji, N. Siddiki, T. Nantung, D. Kim, J. The Sci. World 2014 (2014)

6. M. Zaman, and N. Khoury, Effect of Soil Suction and Moisture on Resilient Modulus of Subgrade Soils in Oklahoma (No. ORA 125-6662) (2007)

7. A. Maher, T. Bennert, N. Gucunski, W.J. Papp Jr., Resilient Modulus Properties of New Jersey Subgrade Soils (No. FHWA NJ 2000-01) (2000)
8. P.R. Fleming, C. Rogers, M.W. Frost, A. Dawson, Int. Symp. on Sub-Drainage in Roadway Pavement and Subgrade, Spain (1998)

9. K.P. George, Prediction of Resilient Modulus from Soil Index Properties, Final report, No. FHWA/MSDOT-RD-04-172, Missisippi Department of Transportation (2004)

10. N.M. Toohey, M.A. Mooney, R.G. Bearce, J. Geotech and Geoenvironmental Eng. 139 (11) 19821985 (2013)

11. A. Cabrera, Evaluation of the laboratory resilient modulus test using a New Mexico Subgrade Soil, Master Thesis, The University of New Mexico (2012)

12. M.S. Hossain and W.S. Kim, Estimation of Subgrade Resilient Modulus for Fine-Grained Soil from Unconfined Compression Test, Transportation Research Record, 2473(1), 126-135 (2015)

13. M. Vogrig and A. McDonald, A Laboratory Technique for Estimating the Resilient Modulus Variation of Unsaturated Soil Specimens from CBR and Unconfined Compression Tests, Doctoral dissertation, Lakehead University (2003)

14. A. Zainorabidin and D.H. Agustina, MATEC Web of Conferences 195. 03010). EDP Sciences (2018)

15. AASHTO Guide for Design of Pavement Structures, American Association of State Highway and Trnsportation Officials, Washington, DC (2003) 